\title{
HEGEMONIA E IMPÉRIOS ORIENTAIS EM HERÓDOTO ${ }^{1}$
}

\author{
Matheus Treuk Medeiros de Araujo*
}

\begin{abstract}
RESUMO: A palavra grega $\mathfrak{\gamma \varepsilon \mu o v i ́ \eta ~ f i g u r a ~ a l g u m a s ~ v e z e s ~ n a s ~ H i s t o ́ r i a s ~}$ de Heródoto. Em muitos desses casos, o termo é usado para designar realidades helênicas, em especial o comando militar da aliança contra os persas durante as Guerras Médicas. Não obstante, um conjunto igualmente relevante de ocorrências diz respeito aos impérios do Oriente Próximo, denotando os reinos persa ou medo, algo inusitado na Grécia clássica. Considerando o desenvolvimento semântico do vocábulo

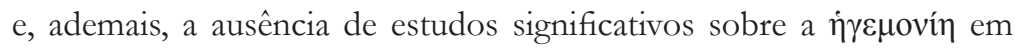
contextos orientais, necessário se faz um estudo sistemático de seus usos em Heródoto. As conclusões sobre o significado e alcance do termo nesse período refletem as circunstâncias históricas da composição herodotiana, bem como as intenções específicas do autor, trazendo possíveis balizas ao exame de seu desenvolvimento subsequente.
\end{abstract}

PALAVRAS-CHAVE: Hegemonia; Império; Heródoto; Oriente Próximo.

\section{HEGEMONY AND ORIENTAL EMPIRES IN HERODOTUS}

* Doutorando em História Social pela Universidade de São Paulo. Membro do Laboratório do Antigo Oriente Próximo (LAOPUSP). mathtreuk@gmail. com

\begin{abstract}
Ancient Greek word $ү \gamma \varepsilon \mu$ ovín occurs a few times in Herodotus' Histories. In many of these cases, the word is used to designate Greek realities, particularly the military command of the alliance against the Persians during the Persian Wars. However, an equally meaningful set of occurrences is related to Near Eastern empires, such as the Median and Persian realms, a very uncommon usage in classical Greece. In the light of its further semantic development and due to the lack of satisfactory studies concerning $\grave{\eta} \gamma \varepsilon \mu$ oví $\eta$ as an eastern phenomenon, systematic study of the word and its uses in Herodotus are still necessary. Our conclusions on the meaning and reach of the word at this time reflect the historical
\end{abstract}

\footnotetext{
${ }^{1}$ Trabalho desenvolvido com bolsa da Fundação de Amparo à Pesquisa do Estado de São Paulo (FAPESP) e estágio de doutorado sanduíche na École Française de Rome financiado pela Coordenação de Aperfeiçoamento de Pessoal de Nível Superior (CAPES).
} 
circumstances of Herodotus' composition, as well as the author's particular intentions, suggesting possible limits to the study of the term's further development.

KEYWORDS: Hegemony; Empire; Herodotus; Near East.

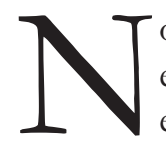

o estudo da geopolítica e das relações internacionais, muitos são os termos empregados para descrever a subordinação de Estados, nações e países a outros entes estatais, ou, inversamente, a fim de expressar uma relação de dominação. Fala-se em império, nas suas variedades direta ou indireta, como o "império britânico" e o norte-americano. Invocam-se as noções de vassalagem, "Estado cliente" ou protetorado. E, amiúde, emprega-se a palavra hegemonia para definir uma posição assumida por entes estatais em relação a outros. Mas, afinal, o que é hegemonia?

Modernamente, trata-se de um termo empregado pela ciência política para expressar a supremacia de facto ou o poder diretivo de um Estado sobre outros de um ponto de vista cultural, militar ou econômico. Um Estado hegemônico exerce, mediante tal preeminência, orientação, influência e até fascínio sobre as demais comunidades de um sistema internacional, imprimindo-lhes, sem emprego direto da força, algum grau de controle e servindo-lhes, ademais, como modelo (Belligni, 1998, p. 589). Nesse panorama, a hegemonia diferiria do puro "domínio", conceito denotando um exercício de poder coativo e direto, já que seria dotada de maior legitimidade e reservaria alguma margem de autonomia aos entes hegemonizados.

$\mathrm{Na}$ teoria marxista de Antonio Gramsci, o vocábulo passou a ser empregado igualmente para se referir às relações de poder entre classes sociais. Mais especificamente, a ordem sociopolítica imaginada por Gramsci encontraria seu fundamento na combinação de força e consenso, uma face do que o autor chamou de "hegemonia", a direção moral das classes dominantes sobre as dominadas (a ponto de fazer estas últimas aceitarem passivamente seu controle político). De fato, os Quaderni del carcere descrevem a noção de hegemonia, em uma de suas acepções, como liderança intelectual e moral exercida pelas classes dominantes sobre as subordinadas, liderança indispensável, em maior ou menor grau, para a sobrevivência do Estado (Fontana, 2000, p. 307-308; Gramsci, 1977, p. 41; 59; Octaviani, 2014, p. 25).

Para onde quer que se olhe, portanto, o uso moderno de hegemonia tem sido associado a contextos de exercício de controle político consentido e, por conseguinte, revestido de alguma aparência de legitimidade. Em geral, essa noção é indissociável do fenômeno "domínio" ou "dominação", partilhando com este uma mesma natureza, em virtude da qual se exerce uma forma de poder de facto, e diferenciando-se, ao mesmo tempo, pela ausência de recurso imediato ou exclusivo à força (Belligni, 1998, p. 589). À diferença de um império, a hegemonia exigiria volição e só poderia existir em meio à soberania externa dos entes hegemonizados. ${ }^{2}$

\footnotetext{
2 "Império" e "Estado" são conceitos movediços que exigem definições flexíveis a fim de servirem como instrumentos heurísticos. Algumas acepções são correntes. $\mathrm{Na}$ Allgemeine Staatslehre, o Estado é,
} 
$\mathrm{Na}$ Antiguidade Clássica, os historiadores gregos e latinos fabricaram suas próprias

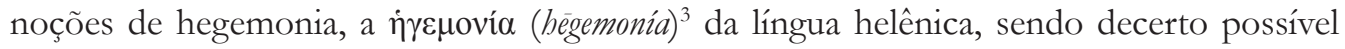
traçar liames entre esta palavra e o conceito moderno. Tal tarefa, de resto, foi encetada há anos por numerosos especialistas.

De acordo com a communis opinio do século XIX, a hegemonia clássica muito se aproximaria da ideia moderna de supremacia (Arnold, 1847, p. 428) e, assim, o legado da Antiguidade não seria apenas morfológico, mas também, em algum grau, semântico. Segundo uma teoria popular inaugurada por George Grote (1851, p. 291, n. 1), Tucídides, o historiador da "Guerra do Peloponeso", teria se empenhado em descrever a transição da

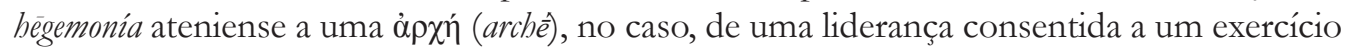
puro de poder sobre os aliados. A fim de amparar tal leitura, Grote procedeu ao seguinte exame terminológico:

Deve-se lembrar que a palavra hegemonia, ou liderança, é extremamente genérica, denotando qualquer caso em que se segue um líder e de obediência, mesmo que temporária, qualificada ou até

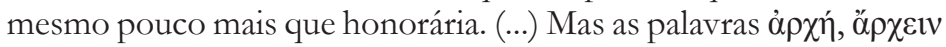
$\alpha \varrho \rho \chi \varepsilon \sigma \theta \alpha$ l, voc. pass., possuem um significado muito menos extensivo e implicam tanto dignidade superior quanto autoridade coercitiva, em maior ou menor grau. (Grote, 1851, p. 291-292, n. 1)

Muitas inferências similares foram realizadas a partir desta distinção. Alguns autores pensaram que Atenas, pólis à qual fora atribuída a prerrogativa da liderança (hégemonía) durante o continuado esforço militar contra os persas, teria, aos olhos de Tucídides, corrompido sua relação com os aliados ao abandonar qualquer pretensão de legitimidade, assumindo uma posição tirânica que, ao fim e ao cabo, culminou na sua derrota contra Esparta durante a Guerra do Peloponeso. A narrativa de Tucídides, nessa perspectiva, seria o relato de uma trajetória imperial fracassada, evidenciando a necessidade de moderação na relação entre Estados hegemônicos e hegemonizados (Lebow, 2001). Em harmonia com tal corolário, Wickersham também reconheceu a distinção fundamental entre hègemonía e arché, alegando, ademais, que a transmutação de uma hegemonia num império se explicaria, na narrativa, pelo caráter impulsivo dos atenienses (Wickersham, 1994, p. 37-61).

A delimitação da hégemonía como uma forma de direção não coativa foi igualmente identificada nos textos dos oradores áticos. Uma posição acadêmica dominante e bastante

grosso modo, entendido como a articulação de três componentes: território, povo e poder coercitivo (Jellinek, 1921, p. 28). Um Império, por sua vez, seria um controle efetivo imposto sobre a soberania de outras sociedades políticas (Doyle, 1986, p. 19) ou um tipo de Estado caracterizado por sua diversidade étnica e ampla extensão territorial (Duverger, 1980, p. 8).

${ }^{3} \mathrm{Na}$ variação ática, mas hègemoníe nos outros dialetos jônicos (Cf. Buck, 1910, p. 19).

${ }^{4}$ Todas as traduções de obras e fontes citadas neste artigo são de nossa autoria, realizadas a partir dos textos estabelecidos pelas edições que se encontram nas referências. A transliteração de termos gregos empregada pelos próprios especialistas foi mantida nas citações. 
convincente destaca o caráter consentido, militar e espontâneo da hegemonia grega nos discursos de Isócrates, Ésquines e Demóstenes (Antela-Bernárdez, 2000, p. 2-5), à semelhança do que supostamente se constata em Tucídides. Deve-se recordar, ainda, o suposto conselho

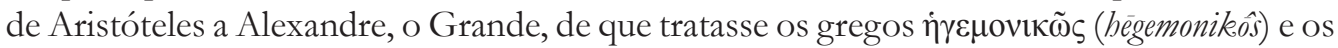
bárbaros $\delta \varepsilon \sigma \pi 0 \tau$ $1 \tilde{\omega} \varsigma$ (despotikếs), como se estes últimos fossem plantas ou animais, indicando a maior dignidade atrelada à primeira forma de comando internacional. ${ }^{5}$

Infelizmente, na atração da aparência, não é sempre trivial o ofício do historiador. $\mathrm{O}$ exame conjunto e sumário da casuística acima poderia sugerir, de um lado, que a hegemonia dos antigos e a hegemonia moderna encontrariam paralelos, seja em razão de certo grau de legitimidade advinda do consentimento dos entes hegemonizados, seja devido à ausência de exercício "nu e cru" da força por aqueles que detêm preeminência. De outro lado, contudo, é preciso realçar as especificidades da visão antiga, a fim de evitar uma abordagem superficial e anacrônica da questão. Nesse sentido, tratar a dicotomia hodierna entre dominação e hegemonia como o amadurecimento progressivo de conceitos tão remotos quanto a Guerra do Peloponeso pode conduzir os especialistas a alguns equívocos.

De fato, nem a leitura de Grote sobre Tucídides é inconteste, nem as fontes antigas permitem atingir um grau coerente de generalização do termo. Na Antiguidade grega e romana, como veremos, hégemonía teve ampla aplicabilidade e pôde, eventualmente, indicar realidades que hoje consideraríamos formas de "dominação" ou "império". À diferença do que por vezes se lê nos modernos, também não se pode negar a natureza precipuamente militar da hegemonia clássica, geralmente vinculada à liderança dentro de uma coalizão ou aliança de cidades-estado. ${ }^{6} \mathrm{E}$, a bem da verdade, a hègemonía antiga padece de tão elevado grau de imprecisão, como notou o próprio Grote, que seria temerário proceder a uma síntese sem redobrada cautela e alguma perspectiva diacrônica.

Heródoto de Halicarnasso, a quem devemos as primeiras ocorrências do termo às quais temos acesso, parece ter muito a nos dizer. E, sem dúvida, "desvendaríamos" o sentido de hègemonie em Heródoto facilmente se pudéssemos sobrepor as interpretações modernas ao variado conjunto de significados fornecido pelas ocorrências da palavra na Antiguidade. Essa abordagem, contudo, é dificultada pelo emprego do vocábulo nas Histórias para descrever entidades políticas orientais, impérios, como o persa, que eram percebidos como particularmente despóticos. ${ }^{7}$ Esse uso, há de se sublinhar, é raramente atestado além das Histórias.

\footnotetext{
${ }^{5}$ Cf. Plutarco, Moralia 329b.

${ }^{6}$ Wilkinson nota que o termo hegemonia foi "deliberadamente revivido" pelos modernos ao longo do século XIX, adquirindo um significado econômico e cultural que originalmente não detinha. Cf. Wilkinson, 2008, p. 119 e ss.

${ }^{7}$ Ou bem Heródoto, como Ésquilo, concebeu uma dicotomia fundamental entre gregos e persas fundada na distinção entre liberdade e tirania (Hartog, 1980, p. 328-345), ou então adotou como objeto central de sua narrativa os temas da dominação e da resistência, acima de qualquer distinção fundamentalmente étnica, enfatizando a trágica e dolorosa dimensão da conquista (Payen, 1997, p. 218). De uma forma ou de outra, sejam (ou não) os persas a via alusiva e indireta de uma crítica a Atenas, e
} 
Ao que tudo indica, os gregos de eras mais remotas desconheciam a palavra bégemonía, da qual a moderna hegemonia é decalque latino, mas conheciam verbos como

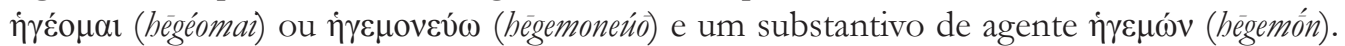
No primeiro caso, o verbo denotava o ato de andar à frente, guiar, orientar, liderar, ser o líder ("marcher devant, aller en tête, guider, être chef de": Chantraine, 1990, p. 405; "vorangehen, führen, den Weg weisen, der Führer sein": Snell, 1979, p. 889), um uso comum em Homero (Odisseia, 14.48; Ilíada, 2.816). A segunda palavra, por sua vez, designava originalmente um comandante de natureza precipuamente militar (Snell, ibidem), como na Iliada, onde denota os comandantes das forças aliadas contra Troia (Ilíada, 2.494-759).

Nos autores clássicos, hègemonía é um termo bastante vago e genérico. Em Platão, por exemplo, aparece relacionado à liderança militar (Leis, 1641a; Eutidemo, 273c) e política (Leis, 4711c), ao comando supremo em uma aliança militar (Crítias, 120d) e à orientação de forma geral (Mênon, 99a). Em sentido lato, a hegemonia de Platão pode ser conferida a elementos (Epinomis, 981c) ou partes do corpo (Timeu, 45b).

$\mathrm{Na}$ Política, de Aristóteles, hégemonía é a liderança militar ou política de Estados, grupos e indivíduos (1272a9; 1285b9-10; 1288a9; 1296a32-39; 1304a23; 1333b.41). ${ }^{8}$ Xenofonte a emprega de forma bastante similar em mais de uma obra (Anábase, 4.7; Agesilau, 2.28-30; Helênicas, 7.1.2). A Constituição dos Atenienses utiliza a palavra como sinônimo de liderança militar (23.1-2) e, em determinada passagem, parece equiparar ou aproximar hégemonía e $\operatorname{arché}^{(24.1-2):}$

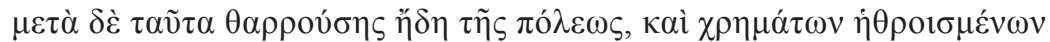

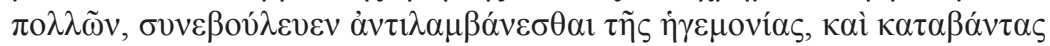

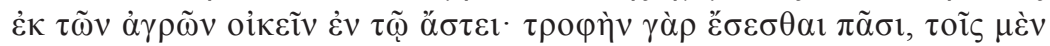

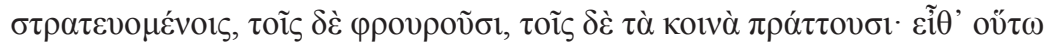

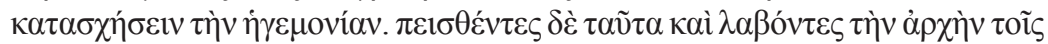

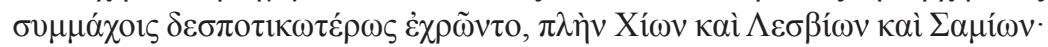

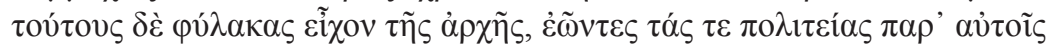

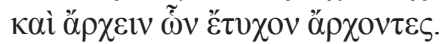

ainda que a dominação absoluta de alguns soberanos fosse tida como adequada a algumas realidades, fato é que o modelo oriental de subordinação internacional é tido como genericamente despótico (senhorial) nas Histórias. Aristóteles, mais tarde, concebeu uma categoria de monarquia específica, a realeza bárbara, caracterizada por uma relação despótica entre governantes e súditos (Política, 1285a). Esse modelo, certamente objeto de alguma censura, seria, contudo, temperado pelo princípio da hereditariedade e a aderência dos monarcas asiáticos às normas. Aristóteles traça explícitos paralelos entre o domínio persa e o império ateniense (Politica, 1284a39-1284b2). Cf. Koebner, 1971, p. 276. ${ }^{8}$ Quando trata das prerrogativas da monarquia “real”, Aristóteles menciona a hégemonía, sem dúvida com o sentido de comando militar (Política, 1285b9-10), algo que se repete na descrição das prerrogativas dos magistrados de Creta (Política, 1272a9). O estagirita também fala de uma hégemonía qualificada "política", implicando uma autoridade civil (Política, 1288a9). Quanto à passagem 1296a39, debatese a identidade do titular da hegemonia e a natureza desse comando (doméstico ou internacional?), como exposto nos comentários da edição de Jean Aubonnet (1971, p. 317, nota 4). 
Depois disso, estando agora confiante a cidade e tendo muitos
bens sido armazenados, ele [Aristides] começou a aconselhar que
tomassem a hegemonia e, após abandonar os campos, residissem na
área urbana, pois haveria alimento para todos: aos que serviam no
exército, aos que faziam vigília e aos que se ocupavam dos assuntos
públicos; e que assim manteriam a hegemonia. Após terem sido
convencidos quanto a essas coisas e tomado o império, trataram
os aliados mais despoticamente, à exceção de Quios, Lesbos e
Samos: a esses tinham como guardiães do império, permitindo-
lhes suas constituições, bem como governar aqueles que por acaso
governavam.

Aparentemente, ao indicar que o conselho de Aristides para a obtenção da "hegemonia" teria sido acompanhado pela aquisição de uma arché, ou império, a Constituição dos Atenienses demonstraria a tênue fronteira entre esses dois termos já na segunda metade do século IV a.C. Espécies de um mesmo gênero, tais noções se comunicavam e, por vezes, poderiam ser intercambiáveis.

Não obstante, se considerarmos que a linguagem de Aristides, citada pelo autor em discurso indireto, fosse temperada por retórica ou decoro, parece provável que hègemonía e arché fossem diferenciadas a essa altura em algum nível. Há, afinal, uma nítida divisão entre o início da passagem, onde o termo hégemonía é parte de um discurso aconselhador, e a conclusão do parágrafo, em que se descreve a sequência dos fatos, com duas ocorrências de archè. A liderança militar, assim, poderia corresponder à face discursiva de um projeto imperial.

O contraste entre hègemonía e archèéé, sem sombra de dúvida, mais nítido nos oradores atenienses, como já foi brevemente mencionado. Ésquines emprega o termo hégemonía ao se referir à possível liderança consentida de Atenas em uma aliança de cidades-estado (Contra Ctesifonte, 58) e o mesmo faz Isócrates ao relembrar um glorioso passado de seus conterrâneos (Areopagítico, 17). Isócrates fala, ainda, da liderança naval dos Atenienses livremente concedida pelos aliados nas Guerras Médicas (Panatenaico, 67). Por essas e outras razões, Balot assevera que "Isócrates distingue genericamente archē de hègemonia em nível terminológico" e afirma que, "apesar da sutil fluidez" de sua terminologia, "ele certamente concebeu uma distinção conceitual entre hegemonia e império" (Balot, 2014, p. 153; Cf. também Poulakos, 1997, p. 81-82).

Christian Bouchet, em volume dedicado à hegemonia em Isócrates, assume posição similar, ainda que mais complexa:

Se a primeira acepção da palavra hegemonia é o comando militar, Isócrates vislumbra, com uma certa modernidade, outras formas de direção e mesmo de presidência. Uma condução dos negócios que rompa com as práticas reputadas injustas e que seja tal que ela mesma conduza a uma forma de felicidade e prosperidade, à eudaimonia, é perfeitamente louvável e invejável; ao contrário, a supremacia e o poder se associando a uma política imperialista e acabando por ser julgado tirânico são odiosos, sobretudo a partir dos anos 350 . (Bouchet, 2014, p. 31) 
Outros usos do termo nos oradores áticos envolvem a liderança dentro de um Estado (Isócrates, Panatenaico 143), a liderança militar numa coalizão (Isócrates, Antídose, 57; Panegírico 17; Ésquines, Contra Ctesifonte, 98), o generalato dos reis espartanos (Isócrates, Carta a Filipe, 33) ou a proeminência internacional (Isócrates, Arquidamo, 110). Em numerosos casos, ademais, o termo é empregado para indicar a presidência em um tribunal (Contra Ctesifonte, 14; 27; 29).

Para Demóstenes, em particular, a hegemonia poderia ser uma forma de liderança internacional ou militar (Quarta Filípica, 6; Contra Neera, 96; Contra Léptines, 68; Pela liberdade dos Ródios, 17; Do tratado com Alexandre, 22) ou espécie de poder e autoridade (Sobre a falsa embaixada, 260; Sobre a Coroa, 65). É notável que a hégemonía de Demóstenes seja recorrentemente associada à noção de "independência" (eleuthería, com o sentido de soberania externa) e contraposta à tirania e à arché no plano internacional. A derrota de Esparta contra Conão é condição para que Atenas novamente aspirasse à hègemonía (Contra Léptines, 68). Não por acaso, Conão é descrito como liberador dos aliados de Atenas (Contra Léptines, 69) e destruidor da tirania e arché de Esparta (Contra Léptines, 70). Como os espartanos, Filipe da Macedônia é acusado de almejar o exercício de uma archée uma tirania sobre todos os gregos (Sobre a Coroa, 66), tendo, para isso, destruído a liberdade e hégemōnía de vários Estados (Sobre a Coroa, 65). É nítido, à luz dessas passagens, o vínculo entre hēgemonía e soberania externa (eleuthería), geralmente contrapostas à arché ou à tirania internacional.

O caso de Tucídides, por sua vez, foi objeto de numerosos comentários. Como já foi notado, uma corrente majoritária atribui ao ateniense a preocupação em diferenciar "hegemonia" de outras formas de poder ou domínio imperiais (Wickersham, 1994, p. 37-61; Lebow, 2001, p. 550), tratando-a como o exercício legítimo de autoridade dentro de uma coalizão militar. Outros autores, minoritários, acreditam que o historiógrafo não forneceria uma distinção com a qual se poderia operar. Tucídides, afinal, "usa hegemonia de maneira intercambiável com arche e strategia. (...) Não há por conseguinte, distinção essencial entre begemonia e arche em Tucídides" (Bloedow, 1994). Ou, nas palavras de Winton, "os termos arche e hegemonia e seus verbos cognatos são regularmente usados de maneira intercambiável" (Winton, 1981, p. 151).

Ao que tudo indica, contudo, assistiria razão à corrente majoritária, ${ }^{9}$ bem sintetizada por Ian Morris:

O ponto de partida óbvio é a terminologia de Tucídides. Ele normalmente apelida a unidade política liderada por Atenas de archê, literalmente "domínio". Ele parece ter distinguido cuidadosamente

\footnotetext{
${ }^{9}$ A hègemonía de Tucídides é, em muitos casos, idêntica ao comando militar de indivíduos, como, por exemplo, Pausânias e Nícias $(1.94 .2 ; 1.130 .1 ; 4.91 ; 5.7 .2 ; 7.15 .2)$. Em tantos outros, parece indicar uma liderança ou comando de uma cidade-estado dentro de uma coalizão (1.76.1; 1.95.6; 1.96.1; 5.47.7; 5.69.1; 6.82.3). Há, por fim, um caso de aparente preeminência política de indivíduos (5.16.1). Os verbos cognatos são usados de forma muito mais genérica. Ao falar do império persa, por outro lado, Tucídides prefere empregar arché (8.43.3), inclusive em sentido territorial (8.48.4).
} 
archê e hêgemonia, "hegemonia", que denotava uma forma de aliança ou controle mais flexível. Em 1.97 ele descreve a aliança consideravelmente consensual anti-persa de 478 como hêgemonia e o controle impopular de Atenas em 431 como archê. (Morris, 2008, p. 128)

As inscrições áticas mais remotas pouco ou nada acrescentam ao problema. Um decreto para o conserto das muralhas do Pireu, datado da segunda metade do século IV a.C., usa a palavra hegemonia com um sentido já notado em Isócrates: a "presidência" de um tribunal (IG II ${ }^{2}$ 244.32). Décadas depois, uma estela ateniense fala de $\dot{\eta} \gamma \varepsilon \mu o v i ́ \alpha$ como "regimentos" (IG II ${ }^{2}$ 657.23). No final do século III a.C., outro decreto parece empregar a palavra para indicar alguma espécie de liderança militar, embora seu estado não permita longas elucubrações (IG II ${ }^{2}$ 843.17).

Mais tarde, no período romano, o termo hégemonía efetivamente amplia seu espectro de significados. ${ }^{10}$ Em documentos diplomáticos da República tardia, hègemonía traduz imperium significando o "Estado" Romano enquanto entidade política e, no Principado, figura na tradução das Res Gestae de Augusto (novamente como versão de imperium), com o sentido de autoridade ou poder imperial (Richardson, 2008, p. 104-105; 118-119). Plutarco fala da magnitude ou extensão de uma hégemonía bárbara, em sentido territorial (Artaxerxes, 6.1; Címon, 18.6). ${ }^{11}$ Diodoro Sículo faz o mesmo ao falar do "império" dos citas $(2.43 .5) \cdot{ }^{12} \mathrm{Em}$ Estrabão, por fim, a palavra chega a ser empregada com o sentido de um império territorial, em referência ao domínio romano (Geografia, 17.3.25; Richardson, 2008, p. 137-138). ${ }^{13}$

\footnotetext{
${ }^{10}$ Nas inscrições do império e do principado, o termo é comumente usado quanto ao reinado dos imperadores romanos, com propósito cronológico (IGL Syr. 3,1: 867; IGL, Syr. 3,2: 1044; SEG 32: 1386; etc.). Em uma inscrição (parcialmente reconstituída por Thomas Drew-Bear) do século IV d.C., denota o império em sentido evidentemente territorial (SEG 31:1116). Não seria demais recordar uma mesma profecia sobre o governo do imperador Galba citada pelos historiadores e biógrafos latinos, nas quais os termos hègemonía, imperium e arché são usados alternadamente e com o mesmo propósito. Em seus Anais, Tácito atribui a Tibério a fala (originalmente em grego) de que Galba também provaria do imperium (6.20). Dio Cássio reporta o discurso direto em grego: "tu também provarás da hégemonía um dia" (57.19.4). Suetônio confere a fala a Augusto e emprega, no lugar de hègemonía, arché (Galba, 4.1). ${ }^{11}$ Plutarco conta que Címon tinha em mente a dissolução de "toda" a hegemonia do rei persa ("ő $\lambda$ \

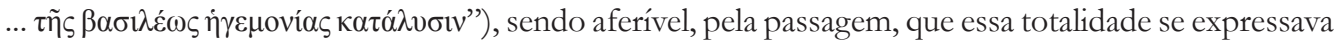
em termos geográficos (Plutarco, Címon, 18.6). Na biografia de Artaxerxes, por sua vez, fala-se da magnitude do império persa, provavelmente em sentido territorial - o que, é verdade, não exclui outra possível (mas improvável) leitura, na qual tal "grandeza" se referiria somente ao elevado grau de dignidade do poder real (Plutarco, Artaxerxes, 6.1).

${ }^{12}$ A hegemonia dos citas nesta passagem pode representar tão somente um poder abstrato com desdobramentos territoriais. De toda forma, é inegável o caráter imperial e despótico dessa autoridade, descrita por Diodoro como a "escravização" de vários povos.

${ }^{13}$ Cf. também Políbio, 1.63.9.
} 
A partir dos casos acima elencados, poderíamos supor que o termo bègemonía, ou hegemonia, iniciou sua carreira como designador de uma liderança militar consentida e, mais tarde, passou a ser empregado igualmente para descrever um exercício de poder coativo, denotando até mesmo territórios imperiais. Heródoto, contudo, já empregara o termo no século $\mathrm{V}$ a.C. para descrever realidades políticas orientais, algo inusitado para uma palavra supostamente atrelada ao exercício de domínio consentido, ao menos se considerarmos a visão predominantemente negativa que os gregos clássicos nutriam de seus adversários persas e medos (Cartledge, 2002, p. 76-77; Hall, 1997, p. 44; Hall, 1989, p. 56-69).

Dezenove são as ocorrências de hégemoníe na obra do historiógrafo de Halicarnasso. Em seis casos, ao contrário do que ocorre nas demais fontes dos séculos V e IV a.C., a palavra designa uma realidade oriental $(1.7 .1,1.46 .1 ; 3.65 .6 ; 7.2 .1,7.8 \mathrm{~A} .1 ; 9.122 .2) .{ }^{14}$ Outras nove ocorrências se referem a um poder exercido por Estados gregos (7.148.4, 7.149.2, $7.159,7.160 .2,7.161 .3 ; 8.3 .1,8.3 .2)$. As restantes dizem respeito à liderança de indivíduos (6.2.1; 7.88.2; 9.10.2) ou até ao comportamento de peixes em cardume (2.93.2). Destarte, resulta que uma proporção bastante significativa de ocorrências não poderia descrever a liderança de Estados gregos numa aliança militar, restringindo-se à caracterização do poder de lídios, persas e medos.

Se fosse ignorada a origem dos entes aos quais se refere, a hegemonia de Heródoto poderia ser separada em duas categorias. De um lado, haveria a hegemonia de indivíduos e dinastias $(1.7 .1,1.46 .1 ; 6.2 .1 ; 7.2 .1,7.88 .2 ; 9.10 .2)$ e, de outro, a hegemonia cujos titulares são povos ou Estados inteiros (3.65.6; 7.8A.1, 7.148.4, 7.149.2, 7.159, 7.160.2, 7.161.3; 8.3.1, 8.3.2; 9.122.2). Em contextos orientais, um exemplo da primeira categoria seria o prólogo da famosa história de Giges e Candaules, reis da Lídia (1.7.1-2):

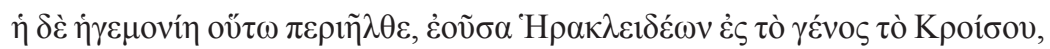

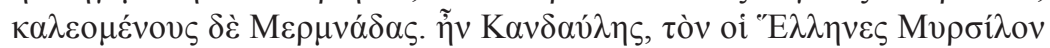

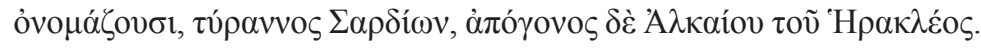

De tal forma a hegemonia, tendo sido dos Heraclidas, passou à estirpe de Creso, chamada Mermnada. Candaules, quem os gregos chamam Mirsila, era rei de Sárdis, descendente de Alceu, filho de Héracles.

Aqui, a hegemonia da qual se fala não parece representar mais do que o poder exercido pela dinastia reinante em Sárdis. O trecho inteiro é uma crônica de sucessões dinásticas, chegando Heródoto a empregar o termo arché com o mesmo propósito que hégemonié ao falar da ascensão dos próprios Heraclidas "por meio de um oráculo" (1.7.4). A Lídia dos Heraclidas, ao que se pode aferir pela narrativa, não era um império, isto é, um domínio coativo sobre outros povos e territórios. Teria sido Giges, primeiro dos Mermnadas, o responsável por uma incipiente expansão (7.14), continuada nos reinados de Árdis, Sadiata, Aliata e, finalmente, Creso, quem Heródoto considera "o primeiro dos bárbaros que nós

\footnotetext{
${ }^{14}$ Demos preferência à divisão da edição de Alfred Denis Godley.
} 
sabemos ter submetido alguns dos gregos ao pagamento de tributo" (1.6.2). ${ }^{15}$ Se hegemonia aqui se referisse a um império ou a um domínio internacional, tal teria provavelmente representado uma contaminação do relato de 1.7.1 pela realidade póstuma de Creso, governante de numerosos povos e mencionado por Heródoto apenas algumas linhas antes.

Como autoridade militar de indivíduos, a hegemonia é atribuída a gregos e orientais sem distinção. Ao descrever a extensão e organização das tropas de Xerxes contra os gregos, Heródoto menciona um incidente ocorrido com Farnuces, general dos persas, que teria adoecido após uma queda, perdendo sua "hegemonia" ou comando das tropas (7.88.2). Da mesma forma, Heródoto nota que Plistarco, filho de Leônidas (o herói das Termópilas), era muito novo para assumir a "hegemonia" que lhe pertencia por direito, restando o comando militar das tropas espartanas nas mãos do notável Pausânias, seu tutor e primo (9.10.2).

Ora, nesses e em outros casos, a hegemonia é antes de tudo uma posição militar de liderança estratégica e hierárquica. Às vezes, vislumbra-se um uso mais genérico, denotando o domínio de autoridades e dinastias, mas seria exagero ver nessas ocorrências a ideia de império ou domínio internacional.

$\mathrm{Na}$ segunda categoria, contudo, de uma hegemonia pertencente a povos e nações, encontram-se exemplos helênicos e bárbaros, todos indicando alguma forma de proeminência internacional. Essa categoria é a que mais interessa, sendo expressão de um uso bastante particular do termo hegemonia.

Das histórias sobre as disputas dos helenos pela "hegemonia", nada de inusitado se extrai. Unidos pela necessidade de fazer frente à Pérsia, mas separados por pretensões inconciliáveis, Esparta, Atenas, Argos e Siracusa disputam recorrentemente pela "hegemonia" ou comando militar supremo das tropas aliadas. Devido ao prestígio que lhe era atrelado, a hègemonié é inclusive condição para a colaboração na guerra e um tema recorrente do sétimo livro das Histórias.

$\mathrm{Na}$ narrativa de Heródoto, os argivos são, em primeiro lugar, instados pelos aliados gregos a contribuir para o esforço de guerra, ao que respondem exigindo metade da "hegemonia" (comando da aliança militar) que lhes pertenceria por direito (7.148.4). Após a recusa dos espartanos, os argivos teriam declarado ser preferível o domínio bárbaro à submissão pelos espartanos (7.149.3), curiosa forma de tratar um comando "por direito". Na passagem seguinte, Heródoto não hesita em chamar a pretensão dos espartanos à hegemonia

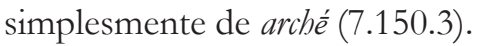

Mais tarde, os gregos procuram a ajuda de Gelão de Siracusa, envolvendo-se em mais um embate retórico pela hegemonia (7.159, 7.160.2, 7.161.3). Por fim, Heródoto lembra que, mesmo tendo sacrificado seu direito à hegemonia durante o embate com Xerxes, os atenienses a recobrariam dos espartanos no futuro (8.3.1-2).

Ao contrário do comando militar das forças gregas, a "hegemonia" de medos e persas é de extremo interesse. A expressão, dissemos, causa espanto, justamente por sugerir que os bárbaros teriam uma forma de domínio similar àquela reivindicada por espartanos e

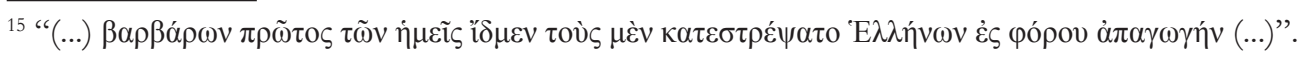


atenienses. Nas três ocorrências desse tipo que encontramos, aliás, o objeto referido parece ser um império de tipo oriental, significando, no mínimo, o exercício de poder coativo de um povo sobre povos, Estados e territórios diversos. As falas de Artembares a Ciro ao final das Histórias (9.122.2), de Cambises aos nobres persas denunciando o golpe de Smérdis (3.65.6) e, por fim, de Xerxes à aristocracia justificando sua política expansionista (7.8A.1) são todos exemplos desse uso da palavra "hegemonia".

De forma alguma poderíamos duvidar de que Artembares se refere a um exercício de poder imperial em 9.122.2, já que este nobre iraniano descreve o vasto controle dos persas em termos demográficos ("muitos homens") e territoriais ("toda a Ásia"). Ainda assim, hègemonié é o termo escolhido para descrever tal entidade:

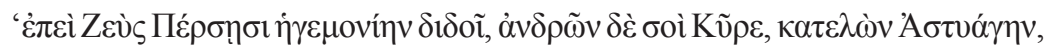

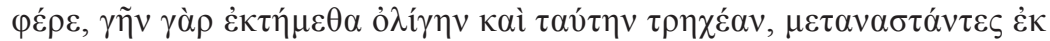

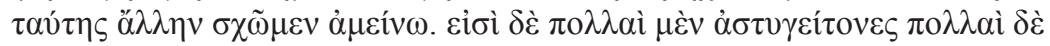

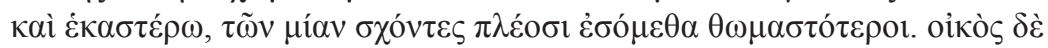

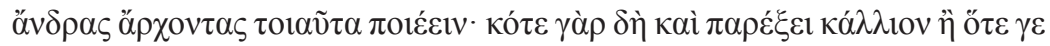

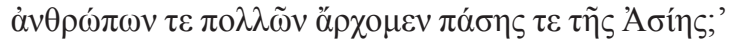

"Uma vez que Zeus entregou a hegemonia aos persas e, dentre os homens, tendo derrotado Astíages, a ti, Ciro, vamos, agora, após abandonar essa terra pequena e dura que possuímos, ter outra melhor. Há muitas terras vizinhas e muitas terras mais distantes. Tomando uma dessas, seremos maior motivo de admiração para muitos mais. É justo que os homens que governam façam isso, pois quando haverá melhor ocasião do que agora que governamos muitos homens e toda a Ásia?” (9.122.2)

Em outra passagem, Xerxes, uma personagem de caráter ambíguo, mas inequivocamente despótico no controle de povos subjugados, fala da "hegemonia" que os persas haviam conquistado com a derrota dos medos: "tal como sou informado pelos anciãos, após tomar aos medos esse império, tendo Ciro destruído Astíages, nunca antes ficamos inativos" (7.8A.1). ${ }^{16}$ Ela se insere na descrição de uma política expansionista e de domínio sobre vários povos, constituindo apologia e justificativa da campanha contra os atenienses, algo marcadamente diferente do que era conhecido como hēgemonía entre gregos, livremente concedida.

Por fim, num trecho célebre da narrativa, Cambises discursa aos nobres persas para confessar o assassinato do irmão e expressar seu último desejo: que os persas não deixassem o poder imperial retornar às mãos dos medos que, por meio de artifícios, haviam recobrado sua autoridade (3.65.6). Mais adiante, Cambises emprega a palavra archécom sentido análogo (3.65.7) e lança uma maldição para incitar os conterrâneos à defesa de sua causa.

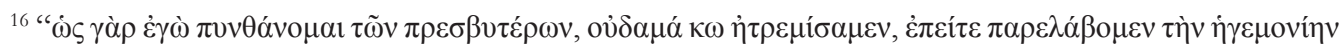

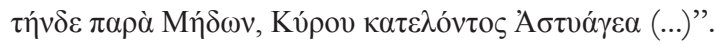


Se, como vimos, a hegemonia indicava preponderantemente um domínio exercido "por direito" e sobre aliados formalmente independentes, o que teria motivado seu uso para descrever um império de tipo oriental, reiteradamente descrito como um exercício de poder despótico ao longo das Histórias? Por que, além disso, uma palavra revestida de tamanha dignidade teria sido empregada para descrever entidades políticas bárbaras, um uso não atestado até muito mais tarde, no auge da Roma imperial?

Os especialistas criaram intrincadas formulações a fim de esclarecer as referidas passagens. Para Payen,

A noção de hegemonie está associada à arkhe em três passagens essenciais do relato, sempre utilizada para designar um poder bárbaro. Pouco antes de morrer, Cambises adjura os nobres aquemênidas presentes "a não tolerar que a hegemonie retorne novamente aos medos", pois seria desse "poder" (arkhen) que dependeriam todos os recursos (karpon) e a liberdade. O último capítulo lembra que, uma vez, Ciro, ao escolher transformar a "hegemonia" dada aos persas por Zeus em um "poder" (arkhein) sobre outrem, renunciava conscientemente aos mesmos frutos admiráveis (karpon thômaston) para evitar a "escravidão". Mais que a hegemonia, que pode simplesmente ser entregue, a arkhe é a escolha concertada de uma forma de dominar, sem a qual não há liberdade. (Payen, 1997, p. 195)

A engenhosa posição de Payen não é de grande ajuda. Se a hegemonia pudesse ser simplesmente dada ou entregue, espanta que esse não seja o caso em nenhuma das três passagens examinadas. Cambises autoriza que a hegemonia seja recobrada por dolo ou pela força, Artembares claramente associa a concessão divina da hegemonia à derrota de Astíages em combate e Xerxes expressamente fala de uma hegemonia tomada aos medos militarmente. Nenhuma dessas hègemoníai foi simplesmente "dada", o que também não é o caso da transição dos Heraclidas aos Mermnadas em outra passagem já analisada.

Da mesma forma, tentar diferenciar a arché da hégemoníe da forma como faz Payen é um exercício hermenêutico incrivelmente difícil. A fala de Ciro em resposta a Artembares meramente indica que os persas perderiam a arché que já detinham se se fixassem em outras localidades. Antes de Ciro, aliás, o próprio Artembares utiliza o verbo árchein para ilustrar a hegemonia dos persas. É praticamente impossível, por fim, evidenciar qualquer diferença na formulação que Cambises faz aos persas empregando arché e hègemoníe alternadamente.

Wickersham adota uma posição mais plausível e aduz que:

Hêgemoniê, no sentido de comando internacional, é quase inteiramente limitada por Heródoto aos casos que eu discuti, dos quais todos dizem respeito ao comando, parcial ou total, da resistência contra Xerxes. Além desse status grego, a palavra denota a posição dos senhores da Tessália (9.1) e do Império Persa. (3.65, 7.8, 9.122) Embora nas últimas três ocorrências a hêgemoniê denote um império oriental, elas não demonstram que Heródoto tenha usado hegemonia 
como sinônimo de arkhê, uma vez que todas as três se encontram em contextos onde a ideia de honra está fortemente associada à hegemonia, precisamente como nos casos gregos. (Wickersham, 1993, p. 21)

Essa interpretação, contudo, é dificultada pelo fato de que Heródoto está precisamente empregando hégemoníe como sinônimo de archéem dois trechos destacados por Wickersham (3.65.6-7; 9.122.1-2). A resposta, portanto, deve residir em outro lugar.

Ao que tudo indica, Heródoto empregou o termo "hegemonia" enquanto comando militar supremo como analogia a fenômenos orientais que lhe eram de custosa designação. É forçoso lembrar que Lídia, Pérsia e Média eram entidades inequivocamente imperiais na narrativa de Heródoto, que dedicou várias linhas a descrever-lhes as numerosas conquistas (em termos de diversidade étnica e territorial). ${ }^{17}$ Tanto a liderança grega quanto o império oriental partilhavam uma natureza comum, na medida em que se referiam à relação de subordinação de uma entidade política a outras, ou de um povo a outros, motivo pelo qual poderiam ser aproximadas em hipóteses específicas.

No século V a.C., os gregos e suas póleis se viram pela primeira vez diante de uma entidade estrangeira de magnitude e natureza radicalmente diversa do que a Grécia havia conhecido até então. Os grandes éthnē da Hélade e arredores poderiam ser Estados extensos, mas continuavam restritos a populações que se identificavam étnica e culturalmente. As póleis gregas continentais, por outro lado, começavam a caminhar rumo ao domínio internacional, mas mesmo a Atenas imperial não chegaria a controlar povos especialmente distantes (ao menos como estes próprios se percebiam) ou um território particularmente vasto (Morris, 2009, p. 133).

Antes disso, os gregos do período arcaico certamente interagiram com Estados orientais que combinavam largas extensões territoriais e diversidade étnica, como a Assíria ou a Lídia, mas esse contato era mais esparso ou menos intenso. Ainda que ignorássemos o grau de interação entre "gregos", ${ }^{18}$ de um lado, e as monarquias orientais, de outro, o fato é que o império da Pérsia foi inédito em magnitude e diversidade demográfica mesmo para os parâmetros orientais. Mais importante, foi apenas (ou precipuamente) no século V a.C. que os gregos desenvolveram gêneros de expressão em prosa inteiramente originais combinados a uma forma igualmente nova de reflexão política.

A associação de um contexto geopolítico inédito à aparição de novas formas de expressão textual exigiu dos autores clássicos uma maneira adequada de enquadrar e referir as monarquias orientais, mas esse processo não deve ter sido simples. Para dar expressão às estranhas realidades do Oriente Próximo, os gregos clássicos fizeram uso de conceitos e palavras com os quais suas audiências estariam familiarizadas. Ésquilo, no início do século V

\footnotetext{
${ }^{17}$ Heródoto, 1.7-16, 72.1-2, 106.2, 188.1, 207 etc.

${ }^{18} \mathrm{~A}$ adequação da categoria para povos de períodos mais remotos esbarra no problema da identidade helênica e a data de sua sedimentação. Seu uso aqui, portanto, é didático. Ressalte-se a importância de sofisticados estudos recentes a esse respeito (Kim, 2013; Skinner, 2012).
} 
a.C., fala da monarquia persa e do império inteiro como uma pólis (Os persas, v. 213; 511-512; 682; 715; 781). Heródoto, na carência de termo melhor, usou hègemonié, entre outras palavras.

Mais que isso, contudo, é notável que Heródoto tenha, por assim dizer, "colocado" o termo hègemonié "na boca" de nobres e reis persas. Em outras palavras, o vocábulo, designando o controle sobre povos e Estados, figura no discurso direto dos orientais, talvez emulando um uso retórico e decoroso empregado pelos próprios gregos (em especial, os atenienses) que não queriam confessar o caráter despótico de seu domínio. Destarte, o uso de hégemonié na fala de persas para se referir a seu próprio domínio internacional deve ter sido um recurso narrativo que ironizava ou apenas representava a tentativa dos bárbaros de mitigar a brutalidade do seu poderio, fazendo com que este se passasse por um controle revestido do verniz da legitimidade. Nesse sentido, apurada seria a opinião de Wickersham sobre a associação da hégemonié a situações de honra e dignidade.

O uso da palavra grega hegemonia para descrever impérios orientais em Heródoto deve, por conseguinte, refletir uma maior dignidade atrelada a esse termo no período clássico, o que ratificaria a corrente majoritária sobre Tucídides e se coadunaria com outros achados do período, como vimos na Constituição dos Atenienses, acima. Por outro lado, sendo muito indeterminada, a terminologia decerto não foi empregada em sentido técnico ou estanque, havendo uma tênue fronteira entre a hegemonia, de um lado, e outras formas de controle, de outro. No período romano, a hegemonia passou a se confundir mais intimamente com outras formas de poder coativo, vindo a ser designação corrente de domínios imperiais, inclusive o próprio Império Romano. Além de adquirir conotação territorial, o termo passou a ser empregado novamente para se referir a impérios orientais, como o persa, da forma que se encontra na biografia de Artaxerxes por Plutarco (6.1).

As aproximações conceituais e terminológicas entre hégemoníe e arché na obra de Heródoto, às quais fizemos referência em alguns momentos, também relevam um aspecto importante do léxico político da historiografia clássica. Quando se recusaram a ceder a hégemoníe aos espartanos, os argivos, na verdade, revelaram considerar aquela liderança uma forma de domínio ou submissão. Ou, em outras palavras, ainda que os espartanos falassem em hègemonié, outros gregos interpretavam tal comando militar em termos de pura dominação (talvez, mas não necessariamente, imperial). Cambises, por outro lado, emprega em seu discurso alternadamente as palavras hègemonié e arché para se referir a uma mesma realidade política, seja porque a arché teria sentido mais lato nesse contexto, seja devido a uma possível confusão entre a realidade despótica do império e o discurso apologético que os grandes reis faziam do mesmo.

A arché, enquanto domínio internacional, é limitada por Heródoto a contextos orientais, com uma suposta exceção (6.98.2). Destarte, é provável que a palavra pudesse então expressar um arranjo institucional de tipo oriental, o império territorial, especialmente quando qualificada, no atributivo ou predicativo, como "grande" (megálê), o que ocorre mais de uma vez ao longo das Histórias $(1.185 .1 ; 1.53 .3 ; 1.87 .3) .{ }^{19}$ Nesse contexto, o termo

${ }^{19}$ Para a mesma expressão, sempre usada para a Pérsia, cf. Xenofonte, Ciropedia, 8.1.13 e Políbio, Histórias, 1.2.2. 
facilmente seria associado à dolorosa realidade da conquista bárbara, carregando conotações negativas. Um exame mais aprofundado do uso de arché nesses contextos, contudo, exigiria uma dissertação à parte, desnecessária para os propósitos ora almejados.

Em conclusão, a análise histórica da palavra hegemonia combinada ao exame sistemático de seu uso em Heródoto permite afirmar que, de fato, o termo teria sido associado ao exercício de poder consentido, adquirindo uma coloração mais prestigiosa se comparado a outros vocábulos do mesmo campo semântico. Esse uso particular, é claro, se restringe à descrição de relações interestatais, sendo comum encontrar a palavra, em outros contextos, com escopo mais genérico: poder, autoridade ou comando. Por analogia, e num momento histórico de desenvolvimentos e contatos inéditos, hégemoníe chegou a ser usada por Heródoto para descrever o domínio de persas e medos sobre outros povos, mas apenas limitadamente e em contextos onde se esperaria uma linguagem mais decorosa. De toda forma, a palavra serviu a diferentes propósitos na Antiguidade, tendo um primeiro significado, mais técnico, vinculado à hierarquia militar, e outros, muito variados, como o de um império territorial durante o Principado. Se, por um lado, o período clássico testemunha uma mais nítida distinção entre hegemonia e domínio coativo, por outro, no período romano, pode-se constatar o uso do termo denotando uma autoridade imperial. Por essa razão, a hégemonié não poderia ser equiparada à hegemonia moderna sem fortes ressalvas.

\section{REFERÊNCIAS}

ANTELA-BERNÁRDEZ, Borja. Hegemonía y panhelenismo: conceptos políticos en tiempos de Filipo y Alejandro. Dialogues d’histoire ancienne, v. 33, n. 2, 2007, p. 69-89. Disponível em: <https://www.cairn.info/revue-dialogues-d-histoire-ancienne-2007-2-page-69.htm>. Acesso em: 21 de março de 2017.

ARISTOTE. Constitution d'Athènes. Traduit par Georges Mathieu; Bernard Haussolier. Paris: Belles Letres, 2002.

ARISTOTE. Politique. Tome I. Texte établi et traduit par Jean Aubonnet. Paris: Belles Lettres, 1960.

ARISTOTE. Politique. Tome II, 1re partie. Texte établi et traduit par Jean Aubonnet. Paris: Belles Lettres, 1971.

ARISTOTE. Politique. Tome II, 2e partie. Texte établi et traduit par Jean Aubonnet. Paris: Belles Lettres, 1973.

ARNOLD, Thomas. The History of the Peloponnesian War by Thucydides. Volume I. Oxford: Whittaker and Co. London, 1847.

BALOT, Ryan K. Courage in the democratic polis: ideology and critique in Classical Athens. Oxford, New York: Oxford University Press, 2014. 
BELLIGNI, Silvano. Hegemonia. In: BOBBIO, Noberto. MATTEUCCI, Nicola. PASQUINO, Gianfranco. Dicionário de Política. Volume 1, $11^{\mathrm{a}}$ Edição. Brasília: Editora UnB, 1998.

BLOEDOW, Edmund F. Review: Hegemony and Greek historians (John Wickersham). Bryn Mawr Classical Review, 1994. Disponível em: <http://bmcr.brynmawr.edu/1994/94.09.02. html>. Acesso em: 21 de março de 2017.

BOUCHET, Christian. Isocrate l'Athénien ou la belle hégémonie. Étude des relations internationales au IV e siècle a.C. Paris: Éditions de Boccard, 2014.

BUCK, Carl Darling. Introduction to the study of the Greek dialects. Grammar, selected inscriptions, glossary. Boston, New York, Chicago, London: Ginn and Company, 1910.

CARTLEDGE, Paul. The Greeks: A portrait of self and others. Oxford: Oxford University Press, 2002.

CHANTRAINE, Pierre. Dictionnaire étymologique de la langue Grecque. Histoire des mots. Paris: Éditions Klincksieck, 1990.

DÉMOSTHÈNE. Plaidoyers politiques. Tome I. Texte établi et traduit par Octave Navarre; Pierre Orsini. Paris: Belles Lettres, 1954.

DÉMOSTHÈNE. Plaidoyers politiques. Tome IV. Texte établi et traduit par Georges Mathieu. Paris: Belles Lettres, 1947.

DÉMOSTHÈNE. Harangues. Tome I. Texte établi et traduit par Maurice Croiset. Paris: Belles Lettres, 1924.

DIODORE DE SICILE. Bibliothèque historique. Tome II, Livre II. Texte établi et traduit par Bernard Eck. Paris: Belles Lettres, 2003.

DOYLE, Michael William. Empires. Ithaca, London: Cornell University Press, 1986.

DUVERGER, Maurice. Le concept d'Empire. Paris: Presses Universitaires de France, 1980.

ESCHINE. Discours. Tome II. Texte établi et traduit par Guillaume Budé; Victor Martin. Paris: Belles Lettres, 1928.

FONTANA, Benedetto. Logos and kratos: Gramsci and the ancients on hegemony. Journal of the History of Ideas, v. 61, n. 2, p. 305-326, April 2000.

GRAMSCI, Antonio. Quaderni del carcere. Vol. 1. Torino: Giulio Einaudi, 1977.

GROTE, George. History of Greece. Vol. 5. Boston: John P. Jewett and Company, 1851.

HALL, Edith. Inventing the barbarian: Greek self-definition through tragedy. New York: Oxford University Press, 1989.

HALL, Jonathan. Ethnic identity in Greek antiquity. Cambridge: Cambridge University Press, 1997. 
HANSEN, Mogens Herman. Polis and City-State. An ancient concept and its modern equivalent. Copenhague: Acts of the Copenhaguen Polis Center, vol. 5, 1998.

HARTOG, François. Le Miroir d'Hérodote: essai sur la représentation de l'autre. Paris: Gallimard, 1980.

HÉRODOTE. Histoires. Livre I. Texte établi et traduit par Philippe-Ernest Legrand. Paris. Belles Lettres, 1956.

HÉRODOTE. Histoires. Livre II. Texte établi et traduit par Philippe-Ernest Legrand. Paris. Belles Lettres, 1982.

HÉRODOTE. Histoires. Livre III. Texte établi et traduit par Philippe-Ernest Legrand. Paris. Belles Lettres, 1949.

HÉRODOTE. Histoires. Livre VI. Texte établi et traduit par Philippe-Ernest Legrand. Paris. Belles Lettres, 1963.

HÉRODOTE. Histoires. Livre VII. Texte établi et traduit par Philippe-Ernest Legrand. Paris. Belles Lettres, 1986.

HÉRODOTE. Histoires. Livre VIII. Texte établi et traduit par Philippe-Ernest Legrand. Paris: Belles Lettres, 1954.

HÉRODOTE. Histoires. Livre IX. Texte établi et traduit par Philippe-Ernest Legrand. Paris: Belles Lettres, 1954.

HERODOTUS. The Persian Wars. With an English translation by Alfred Denis Godley; ed. Heinrich Stein. Cambridge MA, London: Harvard University Press, Loeb Classical Library, 1999.

HOMÈRE. Iliade. Tome I. Chants I-VI. Texte établi et traduit par Paul Mazon. Avec la collaboration de Paul Collart et René Langumier. Paris: Belles Lettres, 1937.

HOMÈRE. Odyssée. Tome II. Chants VIII-XV. Texte établi et traduit par Victor Bérard. Paris: Belles Lettres, 1959.

ISOCRATE. Discours. Tome II. Texte établi et traduit par Georges Mathieu et Émile Brémond. Paris: Belles Lettres, 1928.

ISOCRATE. Discours. Tome III. Texte établi et traduit par Georges Mathieu et Émile Brémond. Paris: Belles Lettres, 1960.

ISOCRATE. Discours. Tome IV. Texte établi et traduit par Georges Mathieu et Émile Brémond. Paris: Belles Lettres, 1962.

JALABERT, Louis; MOUTERDE, René. Inscriptions grecques et latines de la Syrie, III, 1. Région de l'Amanus. Antioche. Paris: Librarie Orientaliste Paul Geuthner, 1950.

JALABERT, Louis; MOUTERDE, René. Inscriptions grecques et latines de la Syrie, III, 2. Antioche. Paris: Librarie Orientaliste Paul Geuthner, 1953. 
JELLINEK, Georg. Allgemeine Staatslebre. Berlin, Heidelberg: Springer-Verlag, 1921.

KIM, Hyun J. The invention of the 'Barbarian' in Late Sixth-Century BC Ionia. In ALMAGOR, Eran; SKINNER, Joseph E. Ancient ethnography. New approaches. London: Bloomsbury, 2013.

KIRCHNER, Johannes (ed.). Inscriptiones Atticae Euclidis anno posteriores. Inscriptiones Graecae II $\left(I G I I^{2}\right) .4$ vols. Berolini: Walter de Gruyter, 1913-1940.

KOEBNER, Robert. Despot and despotism: vicissitudes of a political term. Journal of the Warburg and Courtauld Institutes, vol. 14, n. 3/4, p. 275-302, 1951.

LEBOW, Richard Ned. Thucydides the Constructivist. The American Political Science Review, v. 95, n. 3, p. 547-560, Sept. 2011.

LIDDELL, Henry George; SCOTT, Robert. A Greek-English lexicon. Oxford: Clarendon Press, 1968.

MORRIS, Ian. The greater Athenian State. In: MORRIS, Ian. SCHEIDEL, Walter. The Dynamics of Ancient Empires: State Power from Assyria to Byzantium. New York: Oxford University Press, 2009.

OCTAVIANI, Alessandro. Hegemonia e direito. In: OCTAVIANI, Alessandro. Estudos, Pareceres e Votos de Direito Econômico. São Paulo: Singular, 2014.

PAYEN, Pascal. Les Îles Nomades: Conquérir et résister dans l'Enquête d'Hérodote. Paris: Éditions de l'École des Hautes Études en Sciences Sociales, 1997.

PLATON. Oeuvres Complètes. Tome III, 2e partie. Texte établi et traduit par Alfred Croiset et Louis Bodin. Paris: Belles Lettres, 1923.

PLATON. Oeuvres Complètes. Tome V, 1re partie. Texte établi et traduit par Louis Méridier. Paris: Belles Lettres, 1931.

PLATON. Oewures Complètes. Tome X. Texte établi et traduit par Albert Rivaud. Paris: Belles Lettres, 1963.

PLATON. Oeuvres Complètes. Tome XI, 1re partie. Texte établi et traduit par Édouard de Places (Societas Jesu). Paris: Belles Lettres, 1951.

PLATON. Oeuvres Complètes. Tome XII, 2e partie. Texte établi et traduit par A. Diès et Édouard des Places. Paris: Belles Lettres, 1956.

PLUTARQUE. Vies. Tome VIII. Texte établi et traduit par Robert Flacelière et Émile Chambry. Paris: Belles Lettres, 1972.

PLUTARQUE. Vies. Tome XV. Texte établi et traduit par Robert Flacelière et Émile Chambry. Paris: Belles Lettres, 1979.

PLUTARCH. Plutarch's lives. With an English translation by Bernadotte Perrin. Cambridge MA: Harvard University Press, 1962. 
PLEKET, Henry W.; STROUD, Ronald S. Supplementum Epigraphicum Graecum. Vols. 26-41. Amsterdam, 1979-1994.

POULAKOS, Takis. Speaking for the polis: Isocrates' rhetorical education. Columbia: University of South Carolina Press, 1997.

RICHARDSON, John. The Language of empire: Rome and the idea of empire from the third century $B C$ to the second century AD. Cambridge: Cambridge University Press, 2008.

SKINNER, Joseph E. The invention of Greek ethnography. From Homer to Herodotus. New York: Oxford University Press, 2012.

SNELL, Bruno. Lexicon des Frühgriechischen Epos. Göttingen: Vandenhoeck \& Ruprecht, 1979.

STRABON. Géographie. Tome XV. Texte établi et traduit par Benoît Laudenbach. Paris: Belles Lettres, 2014.

WICKERSHAM, John Moore. Hegemony and the Greek historians. London: Rowman \& Littlefield Publishers, 1994.

WILKINSON, David. Hegemonia: Hegemony, Classical and Modern. Journal of World-Systems Research, v. 14, n. 2, p. 119-141, 2008. Disponível em: <http://jwsr.pitt.edu/ojs/public/ journals/1/Full_Issue_PDFs/jwsr-v14n2.pdf $>$. Acesso em: 21 de março de 2017.

WINTON, Richard I. Thucydides 1, 97, 2: the 'arche of the Athenians' and the 'Athenian Empire'. Museum Helveticum, v. 38, n. 3, p. 147-152, 1981.

XÉNOPHON. Anabase. Tome II. Texte établi et traduit par Paul Masqueray. Paris: Belles Lettres, 1967.

XÉNOPHON. Constitution des Lacédémoniens, Agésilas, Hiéron. Texte établi et traduit par Michel Casevitz. Paris: Belles Lettres, 2008.

XÉNOPHON. Helléniques. Tome II. Texte établi et traduit par J. Hatzfeld. Paris: Belles Lettres 1939. 